\title{
Involving pharmacists in sexual health research: experience from an emergency contraception study
}

\author{
Kirsten Black, Claire Anderson, Ali Kubba, Kaye Wellings
}

\begin{abstract}
Background Community pharmacists are expanding their sphere of activity within primary health care, increasing their role not only in health care but also research.

Methods and results We describe the challenges encountered in carrying out a pilot study of women obtaining emergency hormonal contraception through different providers, including pharmacies, highlighting deficiencies in understanding and experience of the research process, which impacted on the study in substantial ways.
\end{abstract}

Conclusions As pharmacists expand their role, training and professional development will need to be enhanced to support them in their contribution to health care and research.

Keywords community pharmacist, emergency contraception, pharmacy education, pharmacy research

J Fam Plann Reprod Health Care 2009; 35(1): 41-43 (Accepted 24 June 2008)

\section{Introduction}

Pharmacists can make an important contribution to public health by improving access to emergency hormonal contraception (EHC). ${ }^{1}$ UK health authorities saw the Crown report's recommendation regarding introduction of patient group directions (PGDs) as an opportunity for community pharmacists to supply EHC free of charge. ${ }^{2}$ This was supported by funding from Health Action Zone (HAZ) schemes, set up in areas of deprivation across the UK to address health inequalities, 3,4 which encourage health care providers to find innovative and collaborative ways of increasing health gain. ${ }^{5}$

In January 2001, following establishment of the PGD schemes, levonorgestrel EHC (Levonelle ${ }^{\circledR}$ ) was deregulated to a pharmacy $(\mathrm{P})$ status in the UK and became available in all community pharmacies. The PGD services provided EHC free of charge, while other pharmacies charged a fee ( $£ 24.99$ in 2008). Since deregulation, women have shown increasing preference for pharmacy over clinical provision of EHC. ${ }^{6}$ The expansion of pharmacists' roles into sexual health has been accompanied by research to evaluate these developments. Methods used to assess pharmacy EHC supply have included questionnaire surveys, focus groups and mystery shopper studies.7,8 Some studies have used population-based samples $;{ }^{9}$ others have recruited through pharmacists at the point of provision. ${ }^{10}$

Department of Obstetrics and Gynaecology, University of Sydney, Sydney, Australia

Kirsten Black, FRANZCOG, MFSRH, Senior Lecturer

School of Pharmacy, University of Nottingham, Nottingham, UK

Claire Anderson, PhD, MRPharms, Professor of Social Pharmacy

Department of Reproductive and Sexual Health Services, Lambeth Primary Care Trust, London, UK

Ali Kubba, FRCOG, FFSRH, Lead Consultant

Centre for Sexual and Reproductive Health Research, London School of Hygiene and Tropical Medicine, London, UK

Kaye Wellings, FRCOG ad eundem, FFPH, Professor of Sexual and Reproductive Health

Correspondence to: Dr Kirsten Black, Department of Obstetrics and Gynaecology, QEII Research Institute, Building D02,

University of Sydney, Sydney, NSW 2006, Australia.

E-mail:kblack@med.usyd.edu.au

\section{Key message points}

- Whilst pharmacists are rapidly expanding their clinical knowledge and skills, there has been less focus on developing competency with research.

- The experience of working with pharmacists to undertake a study of emergency hormonal contraception services revealed a willingness amongst pharmacists to participate in research but a lack of familiarity with the research process, which impacted on recruitment.

- Researchers need to be aware of the difficulties facing pharmacists in carrying out research. Professional education needs to prioritise the research component of pharmacy practice.

In this paper we describe some methodological difficulties encountered in a pilot study investigating women's experience of obtaining EHC through pharmacies and clinical services. We discuss how these difficulties threatened continuation and validity of the research to help mitigate the risk of similar problems impeding future research in this important area.

\section{Emergency contraception study}

The methodology of this pilot study is described fully elsewhere. ${ }^{11}$ We recruited a cohort of women obtaining EHC through two types of services between 2002 and 2003 in the inner city South London boroughs of Lambeth and Southwark, with the aim of investigating short-term impact within different service models. We asked medical staff and pharmacists to recruit women at the time they presented. Willing volunteers recorded their contact details on an information sheet and were contacted and interviewed 4 months later. Of the five pharmacies taking part in the study, two were involved in the HAZ scheme and three were selling EHC over the counter (attendance was lower at these premises compared to the HAZ pharmacies). ${ }^{2}$ Pharmacists were paid for their time and none refused involvement.

\section{Methodological issues}

Many of the pharmacists were familiar with audit, but few had participated in clinical research. A key challenge related to sample recruitment and response rates. We could not recruit directly from HAZ pharmacies as the contract held with local health authorities prohibited third-party disclosure of information. Instead the pharmacists themselves agreed to recruit on our behalf. However, most were unable to record numbers approached to participate 
because of the demands of business and so we had no denominator for the response rate.

A second difficulty related to speed of recruitment. In pharmacies selling EHC over the counter, study enrolment was slow because fewer women were buying from this source. The HAZ pharmacies, by contrast, were extremely busy, yet in one case recruited few women. The lead pharmacist admitted his discomfort with the interaction around EHC, particularly in dealing with the younger women, and was reluctant to request participation in the research.

A third challenge related to confidentiality and we encountered one serious breach thereof. Despite having been briefed on the importance of ensuring confidentiality, and the importance of storing volunteer details behind the counter, staff in one pharmacy placed the box containing names on the counter, believing that women were more likely to volunteer if they felt they were not been scrutinised. On one occasion, a box containing details of up to 10 women went missing. The pharmacist notified the police and we notified the ethics committee and temporarily suspended the study at all sites pending investigation. The committee's recommendation, that the boxes be fixed to the counters at each of the sites, was not considered feasible but we proposed instead that the pharmacists should sign a document stating that the patient details would be kept locked away at all times, and that none would be left in a public area. All participating pharmacists agreed to this and the ethics committee consented to the continuation of the study, but some momentum was lost. Supported by advice from a statistician, we decided to cease recruitment at 50 women.

\section{Ethical approval}

Ethical approval for this study was granted by Guy's and St Thomas' Research Ethics Committee.

\section{Discussion}

This paper illustrates some of the challenges involved in undertaking sexual health research in pharmacies. The findings of the study, reported fully elsewhere, suggested that women experienced less privacy and comfort in pharmacies compared with those attending a clinical service. ${ }^{11}$ This may also have impacted on the research process. Lack of experience of, and familiarity with, the research process led to difficulties of confidentiality and recruitment.

These challenges apply to all health care providers, but are exacerbated in the context of pharmacies by commercial pressures. ${ }^{12}$ There will inevitably be incompatibility between the requirements of running a business and carrying out research. Further, at a time when pharmacists were grappling with the relatively new responsibility of EHC supply, taking on additional responsibilities of recruitment for research may have seemed overwhelming.

As researchers, we had not adequately anticipated the difficulties of maintaining control over the research process, of ensuring patient confidentiality, and of achieving compliance with the research - all of which have been reported by others. ${ }^{13}$ Studies of emergency contraception undertaken in pharmacies have routinely achieved response rates lower than $10 \% 10,14-17$ and this has similarly been attributed to moral opposition to EHC, time constraints, sensitivity of the issues, and unwillingness to add to the administrative burden.

Despite the difficulties, the benefits of academic research in community pharmacies can be reciprocal. Members of a community pharmacy research network established in the North of England reportedly enjoy the exposure to different research methods, and believe that involvement in research improves their relationships with customers and the advice they give. ${ }^{18}$ Alongside the expansion of pharmacists' responsibilities, ${ }^{19}$ professional development programmes have been set up to update them on the changing needs in pharmacy practice and to develop their clinical skills. Pharmacists are developing a broader understanding of the research process and how to interpret research findings and translate them into clinical practice. ${ }^{20}$ Practical issues, such as lack of privacy, are being addressed. A new contractual framework for pharmacists includes provision of a consultation area as a specification for many services and as many as $75 \%$ of pharmacies now provide a private area. ${ }^{21}$

It will take time for the necessary training in research methods to be implemented, and to influence practice. ${ }^{22}$ Meanwhile, researchers need to ensure that the process is as convenient as possible, that it does not conflict with commercial goals, that the necessary equipment is provided, and that time is spent fully briefing pharmacists on the rationale for the procedures used. We hope that the lessons we learnt in the course of this study may benefit others.

\section{Acknowledgements}

The authors wish to thank the study pharmacists for their involvement and Beth Taylor and Tony Carson for their guidance.

\section{Statements on funding and competing interests}

Funding Dr Kirsten Black was granted a Research Training Fellowship from the Guy's and St Thomas' Charitable Foundation to undertake this study as part of a PhD. Schering Health Care contributed funds for the consumable costs of the study. Competing interests None identified.

\section{References}

1 Royal Pharmaceutical Society of Great Britain. Contraception and sexual health. Pharmaceutical Journal 1999; 262: 873.

2 Lambeth Southwark and Lewisham Health Action Zone. A Timely Service. A Lambeth, Southwark and Lewisham Health Action Zone Project on Access to Emergency Hormonal Contraception via Accredited Pharmacies. 2001. http://www.lho.org.uk/download.aspx?urlid=8753\&amp;urlt=1 [Accessed 12 March 2008].

3 Anderson C, Bissell P, Sharma S, Sharma R. Lambeth Southwark and Lewisham Health Action Zone Report into the Provision of Emergency Contraception in Community Pharmacy Via Patient Group Directions. Nottingham, UK: University of Nottingham, 2001.

4 Savage I. Community Pharmacy Supply of Emergency Contraception Under a Patient Group Direction: "A Service Begging To Be Done”. London, UK: Pharmacy Practice Group, King's College London, 2001.

5 Health Development Agency. Lessons from Health Action Zones. London, UK: Health Development Agency, 2004.

6 Marston C, Meltzer H, Majeed A. Impact on contraceptive practice of making emergency hormonal contraception available over the counter in Great Britain: repeated cross sectional surveys. BMJ 2005; 331(7511): 271.

7 Cohen MM, Dunn S, Cockerill R, Brown T. Using a secret shopper to evaluate pharmacist provision of emergency contraception. Can Pharm J 2004; 137: 28-33.

8 Anderson C, Bissell P. Using semi covert research to evaluate an emergency hormonal contraception service. Pharm World Sci 2004; 26: 102-106.

9 Moreau C, Bajos N, Trussell J. The impact of pharmacy access to emergency contraceptive pills in France. Contraception 2006; 73: 602-608.

10 Killick SR, Irving G. A national study examining the effect of making emergency hormonal contraception available without prescription. Hum Reprod 2004; 19: 553.

11 Black K, Mercer C, Kubba A, Wellings K. Provision of emergency contraception: a pilot study comparing access through pharmacies and clinical settings. Contraception 2008; 77: $181-185$.

12 Departments of General Practice and Primary Care and Management Studies University of Aberdeen. Community Pharmacy Service Delivery and Organisation $R$ and $D$ 
Programme Evolution and Change in Community Pharmacy. London, UK: Royal Pharmaceutical Society of Great Britain, 2003.

13 Weinberg M, Murray M, Marero D, Brewer N, Lykens M, Harris $\mathrm{L}$, et al. Issues in conducting randomised controlled trials of health services research interventions in non-academic practice settings: the case of retail pharmacies. Health Serv Res 2002; 37: 1067-1077.

14 Gardner JS, Hutchings J, Fuller TS, Downing D. Increasing access to emergency contraception through community pharmacies: lessons from Washington state. Fam Plann Perspect 2001; 33: 172-175.

15 Wells ES, Hutchings J, Gardner JS, Winkler JL, Fuller TS, Downing $\mathrm{D}$, et al. Using pharmacies in Washington State to expand access to emergency contraception. Fam Plann Perspect 1998; 30: 288-290.

16 Sommers SD, Chaiyakunapruk N, Gardner JS, Winkler J. The emergency contraception collaborative prescribing experience in Washington State. J Am Pharm Assoc 2001; 41: 60-66.

17 Sucato GS, Gardner JS, Koepsell TD. Adolescents' use of emergency contraception provided by Washington State pharmacists. J Pediatr Adolesc Gynecol 2001; 14: 163-169.

18 Seston E, Hassell K, Cantrill J, Nicolson M, Noyce P, Schafheutle E. Experiences of establishing and maintaining a community pharmacy research network. Primary Health Care Res Develop 2006; 4: 245-255.

19 Adamcik BA, Ransford HE, Oppenheimer PR, Brown JF, Eagan PA, Weissman FG. New clinical roles for pharmacists: a study of role expansion. Soc Sci Med 1986; 23: 1187-1200.

20 Gilbert H, Mills E, Ward E. How can community pharmacists become involved in practice research? Pharmaceutical Journal 2006; 276(7385): 104

21 Pharmacy Practice Research Trust. Evaluation of the Implementation of the Community Pharmacy Contractual Framework in England and Wales. Q\&As on Community Pharmacy Contractual Framework Briefing Paper. London, UK: Pharmacy Practice Research Trust, 2007.

22 Guest D, Oakley P, Budjanovcanin A. Pharmacy Academics Workforce Strategy. Executive Report. Key Findings and Policy Options. London, UK: King's College London, 2007.

\section{FACULTY OF SEXUAL \& REPRODUCTIVE HEALTHCARE AWARDS}

The Faculty of Sexual and Reproductive Healthcare has available a number of annual awards for which applications are invited from Faculty members and non-members. Details of the individual awards, together with an application form and/or guidelines on how to apply and any eligibility criteria, may be found on the Faculty website at www.fsrh.org.

\section{Margaret Jackson Prize Essay}

The Faculty will award three prizes annually in memory of Dr Margaret Jackson, a distinguished pioneer in the field of family planning. These prizes are awarded to undergraduates who write the three best essays on a topic related to reproductive health care or fertility control. The first prize is $£ 300$, with $£ 100$ each for the two runners-up. Entries should not exceed 3000 words.

Eligibility: Individuals (undergraduate medical students)

Closing date: 24 March annually

The David Bromham Annual Memorial Award

David Bromham was the first Chairman of the Faculty of Family Planning and Reproductive Health Care (as the Faculty was then known). Sadly, halfway through his second term of office he became ill, and in 1996 he died. His loss was tragic, not only for the Faculty, but for the family planning movement in Britain and worldwide. Whilst in Leeds he set up an assisted conception programme, which was and is one of the most successful in the world. In 1991 he set up a fertility control unit designed to provide a more accessible service for the termination of pregnancy. He also carried out an extensive programme of research and was closely involved with the British Journal of Family Planning (now the Journal of Family Planning and Reproductive Health Care).

The Award is not intended to be a prize for a long and distinguished service, rather for a piece of work which through inspiration, innovation or energy has furthered the practice of family planning and reproductive health care in any way and any setting. It is not a research grant. Younger health professionals sometimes undervalue their achievements but they are exactly the people that David Bromham would have wished to see encouraged as this award now acknowledges.

The award will be made either to an individual (who must be a current Diplomate, Member or Fellow of the Faculty) or to a team, which could be multidisciplinary. In the latter case, the lead doctor should be a current member of the Faculty. You may nominate yourself or your team or be nominated by someone else.

Eligibility: Individuals (Faculty members) or teams Closing date: 7 April annually

International Travelling Scholarship of the Faculty

The Faculty offers a scholarship for those Faculty members who are interested in going abroad to visit international colleagues, services, research or educational establishments in order to learn about some aspect of family planning or reproductive health care. The award will be for a maximum of $£ 2000$. The recipient of the award will be required to give a presentation at a Faculty conference.

Eligibility: Individuals (Faculty members) Closing date: 7 April annually

The 4-0-8 Sheffield Fund

In 2001, the 4-0-8 Young People's Consultation Centre Ltd, Sheffield made a significant donation to the Faculty for the purpose of funding training for health care professionals who have limited funding for attending training meetings. Any person working in the field of reproductive and sexual health care within the UK may apply. Approximately $£ 4000$ is allocated annually, divided between the successful applicants.

Eligibility: Individuals (Faculty members/non-members)

Closing date: See website for details 